Proc. of the 15th Int. Workshop on Slow Positron Beam Techniques and Applications, Prague, September 2-6, 2019

\title{
Positron Spectroscopy of Hydrogen-Loaded Ti-6Al-4V Alloy with Different Defect Structure
}

\author{
R. Laptev*, N. Pushilina, E. Stepanova And M. Syrtanov \\ Division for Experimental Physics, National Research Tomsk Polytechnic University, \\ Lenin Av. 30, 634050, Tomsk, Russia
}

\begin{abstract}
The defect structure of annealed cast, electron beam melted and ultrafine-grained titanium Ti-6Al-4V alloys before and after hydrogenation was studied. It has been established that before hydrogenation the predominant types of defects in electron beam melted and ultrafine-grained titanium alloy are dislocations and low-angle boundaries, respectively. The cast alloy after annealing is defect-free material. Hydrogenation from the gas phase to $1.00 \pm 0.15 \mathrm{wt} \%$ leads to an increase of the concentration of the predominant type of defects. Moreover, vacancy complexes also presented in electron beam melted and ultrafine-grained Ti-6 Al-4V alloys interact with hydrogen and form hydrogen-vacancy complexes.
\end{abstract}

DOI: 10.12693/APhysPolA.137.242

PACS/topics: 61.72.Ff, 61.82.Bg, 78.70.Bj

\section{Introduction}

The presence of hydrogen in metals is an essential technical and scientific problem, since hydrogen, penetrating in structural materials, initiates the formation of various types of defects and significantly affects physical and mechanical properties of metals and alloys [1-6]. Hydrogen embrittlement leads to accelerated depletion of the constructional element resource, which is especially characteristic in cases of the development of damage accumulation processes localised near various defects in the metal structure. Due to the specifics of metal-hydrogen system monitoring, periodic control should be based on nondestructive methods that are sensitive either to changes in the physical and mechanical properties of the material or to the direct hydrogen accumulation.

A comparative analysis of experimental data showed that positron spectroscopy, which is highly sensitive and allows determining not only the type and concentration of defects but also the chemical environment, is localised for monitoring the hydrogen interaction with defects and revealing the mechanisms of formation of defects of hydrogen origin. Nowadays, positron spectroscopy methods are increasingly used to control advanced structural materials $[7,8]$. Therefore, metals and alloys obtained using additive technologies may have a specific structure that is formed during the manufacturing process (lamellar structure, columnar grains, micro- and nanoscale precipitates of secondary phases, developed dislocation structure). At the same time, ultrafine-grained (UFG) materials obtained by methods of severe plastic deformation (SPD) are characterised by the presence of a large number of defects of various dimensions in the crystal structure, such as vacancies and their complexes, dislocations, and boundaries of different types [9-11].

*corresponding author; e-mail: laptevrs@tpu.ru
The presence of specific defects and other inhomogeneities has a significant effect on the structure, mechanical properties, corrosion, and hydrogen resistance of metals and alloys obtained using additive methods and methods of severe plastic deformation [12-14]. Thus, the purpose of this work is to study the initial defect structure effect on the hydrogen-induced defects accumulation in a titanium alloy.

\section{Materials and methods}

For the study, samples were prepared in different microstructural states: cast material, samples produced by electron beam melting (EBM Ti-6Al-4V alloy), and samples obtained using methods of severe plastic deformation (UFG Ti-6Al-4V alloy). Samples in the cast state were annealed at a temperature of $750^{\circ} \mathrm{C}$. The EBM Ti-6Al-4V samples were built using an electron-beam melting 3D-printer designed in Tomsk Polytechnic University [15]. The Ti-6Al-4V powder was supplied by "Normin" Ltd. (Russia), the average particle size of the powder was $70 \mu \mathrm{m}$. The samples were blocks with dimensions of $20 \times 20 \times 1 \mathrm{~mm}^{3}$. The samples were manufactured at the scanning rate of $16 \mathrm{~mm} / \mathrm{s}$, and the substrate temperature of $\approx 750^{\circ} \mathrm{C}$.

The UFG state in cast $\mathrm{Ti}-6 \mathrm{Al}-4 \mathrm{~V}$ alloy was obtained by comprehensive pressing with a change in the deformation axis and a gradual temperature decrease in the range of $600-580^{\circ} \mathrm{C}$ (ISPMS SB RAS, Tomsk) [16].

Hydrogen saturation was carried out on a Gas Reaction Controller LPB by Advanced Materials Corporation according to the Sieverts method. The source of hydrogen is a Proton HyGen 200 hydrogen generator (the purity of the generated hydrogen is $99.9995 \%$ ). Hydrogenation occurred automatically at a temperature of $600^{\circ} \mathrm{C}$ (heating rate of $4{ }^{\circ} \mathrm{C} / \mathrm{min}$ ) and a hydrogen pressure of $67 \mathrm{kPa}$ in the chamber. Cooling took place in a vacuum at a rate of $1.5^{\circ} \mathrm{C} / \mathrm{min}$. The average concentration for all hydrogenated samples, determined by melting in an inert gas, was $1.00 \pm 0.15 \mathrm{wt} \%$. 
A semi-digital positron spectrometric complex was used for studying the evolution of the defect structure of metals and alloys upon hydrogen saturation. In this complex, the methods of positron annihilation lifetime spectroscopy (PALS) and the coincidence analysis of the Doppler broadening of the annihilation spectroscopy (CDBS) are integrated. The time resolution and count rate of PALS module were $170 \pm 7 \mathrm{ps}$ and $90 \pm 30$ counts/s, respectively. For CDBS module the energy resolution was $1.16 \pm 0.03 \mathrm{keV}$ at $116 \pm 15$ counts/s count rate. The source of positrons was an isotope ${ }^{44} \mathrm{Ti}$ with $0.91 \mathrm{MBq}$ activity. For individual samples, one two-dimensional CDBS spectrum and two PALS spectra were obtained with good statistics $\left(3 \times 10^{6}\right.$ for PALS and $4 \times 10^{7}$ for CDBS). The analysis was carried out according to a three-component trapping model using the LT10 software package $[17,18]$. The contribution of the positron source was $5.9 \%$ for titanium alloys, associated with annihilation in radioactive salt $\left(\tau_{1}=305 \pm 1\right.$ ps with a relative intensity of $71.7 \%$ ) and the annihilation of orthopositronium $\left(\tau_{2}=1779 \pm 10 \mathrm{ps}\right.$ with a relative intensity of $28.3 \%$ ). The CDBTools program package [19] was used for CDBS spectra processing through $S$ and $W$ parameters analysis obtained for $O X$ cross-section of the twodimensional spectrum [7, 20].

The structural and phase state of the obtained samples was examined using X-ray diffraction analysis, scanning and transmission electron microscopy.

\section{Results and discussion}

In the initial state, cast $\mathrm{Ti}-6 \mathrm{Al}-4 \mathrm{~V}$ alloy has an inhomogeneous structure consisting of $\alpha$ single-phase and $(\alpha+\beta)$ two-phase regions. The single-phase regions $10-40 \mu \mathrm{m}$ in size, as a rule, are surrounded by the two-phase regions. In the single-phase regions, grain structure with dimensions of $3-5$ and $7-10 \mu \mathrm{m}$ is observed in transverse and longitudinal sections, respectively. According to the data of X-ray diffraction analysis, the volume fraction of $\beta$ phase in this state of the alloy is 5 vol.\%.

The internal grain structure of the EBM Ti-6Al-4V samples is represented by $\alpha$-phase plates, along which $\beta$-phase layers are located. The $\alpha$-phase plates form colonies similar to the perlite colonies in steel. The thickness of the alpha-phase plates is predominantly $9 \mu \mathrm{m}$, but plates with a thickness of $200 \mathrm{~nm}$ are also observed in EBM alloy. X-ray diffraction studies have shown that the volume fraction of $\beta$ phase in samples of EBM Ti- $6 \mathrm{Al}-4 \mathrm{~V}$ alloy is equal to 4 vol.\%.

The microstructure of UFG samples is represented by a two-phase $(\alpha+\beta)$ grain-subgrain structure with an average grain size of $0.29 \mu \mathrm{m}$ (Fig. 1). The formation of the UFG structure is found to lead to a slight increase in the volume fraction of the $\beta$ phase (up to 5 vol. \%).

The hydrogenation of cast and UFG titanium alloy samples to a concentration of $1.00 \pm 0.15 \mathrm{wt} \%$ results in the appearance of $\mathrm{Ti}-\mathrm{H}_{x}$ hydride precipitates.
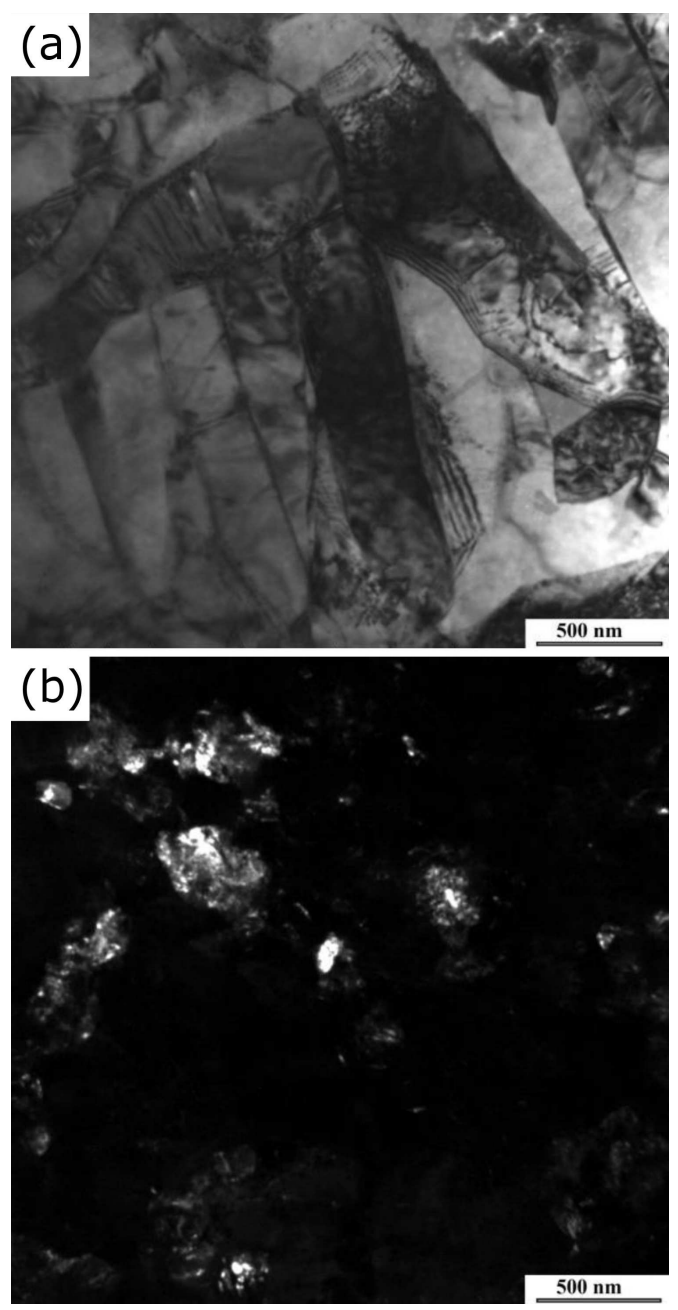

Fig. 1. Electron micrographs of the Ti-6Al-4V alloy: (a) EBM Ti-6Al-4V alloy (bright-field image), (b) UFG Ti-6Al-4V alloy (dark-field image).

At the same time, according to XRD analysis data, after hydrogenation to the same concentration in the EBM Ti- $6 \mathrm{Al}-4 \mathrm{~V}$ alloy, the redistribution of the intensities of diffraction maxima is observed on the corresponding diffraction patterns. The diffraction patterns contain reflections of $\alpha$ phase of titanium, the cubic $\delta$ and tetragonal $\gamma$ phases of titanium hydride, and intermetallic $\mathrm{Ti}_{3} \mathrm{Al}$ phase with hcp lattice.

The results of PALS analysis for the experimental Ti-6Al-4V samples before and after hydrogenation are collected in Table I.

In the cast alloy, there is only one short-lived component $\left(\tau_{F}=147 \pm 1 \mathrm{ps}\right)$ associated with the annihilation of positrons in the titanium lattice [21-26]. Hydrogenation of the cast titanium $\mathrm{Ti}-6 \mathrm{Al}-4 \mathrm{~V}$ alloy up to of $1.00 \pm 0.15 \mathrm{wt} \%$ leads to the appearance of lifetime components: $\tau_{A}=166 \pm 2 \mathrm{ps}$ and $\tau_{B}=276 \pm 6 \mathrm{ps}$ with intensities $I_{A}=83 \%$ and $I_{B}=2 \%$. The component $\tau_{A}=166 \pm 2 \mathrm{ps}$ is related to annihilation of positrons trapped by dislocations in titanium [21, 22]. 
Parameters of positron annihilation in $\mathrm{Ti}-6 \mathrm{Al}-4 \mathrm{~V}$ experimental samples.

TABLE I

\begin{tabular}{l|c|c|c|c|c|c|c|c}
\hline \hline \multicolumn{1}{c|}{ State } & $\tau_{A}[\mathrm{ps}]$ & $I_{A}[\%]$ & $\tau_{B}[\mathrm{ps}]$ & $I_{B}[\%]$ & $k_{A}\left[\mathrm{~ns}^{-1}\right]$ & $k_{B}\left[\mathrm{~ns}^{-1}\right]$ & $\tau_{F}[\mathrm{ps}]$ & $\tau_{\mathrm{avg}}[\mathrm{ps}]$ \\
\hline Cast Ti-6Al-4V & - & - & - & - & - & - & $147 \pm 1$ & $147 \pm 1$ \\
Cast Ti-6Al-4V-H & $166 \pm 2$ & $83 \pm 2$ & $276 \pm 6$ & $2.0 \pm 0.1$ & $4.18 \pm 0.08$ & $0.164 \pm 0.007$ & $147 \pm 1$ & $156 \pm 1$ \\
EBM Ti-6Al-4V & $164 \pm 2$ & $13 \pm 4$ & $290 \pm 5$ & $0.06 \pm 0.03$ & $0.11 \pm 0.03$ & $0.002 \pm 0.001$ & $147 \pm 1$ & $149 \pm 1$ \\
EBM Ti-6Al-4V-H & $166 \pm 2$ & $61 \pm 2$ & $207 \pm 5$ & $14.0 \pm 0.2$ & $2.6 \pm 0.1$ & $0.74 \pm 0.08$ & $145 \pm 2$ & $154 \pm 1$ \\
UFG Ti-6Al-4V & $171 \pm 2$ & $71 \pm 2$ & $293 \pm 5$ & $2.0 \pm 0.1$ & $2.18 \pm 0.04$ & $0.115 \pm 0.004$ & $147 \pm 1$ & $153 \pm 1$ \\
UFG Ti-6Al-4V-H & $167 \pm 5$ & $80 \pm 2$ & $281 \pm 6$ & $0.2 \pm 0.1$ & $3.20 \pm 0.06$ & $0.013 \pm 0.007$ & $147 \pm 1$ & $153 \pm 1$
\end{tabular}

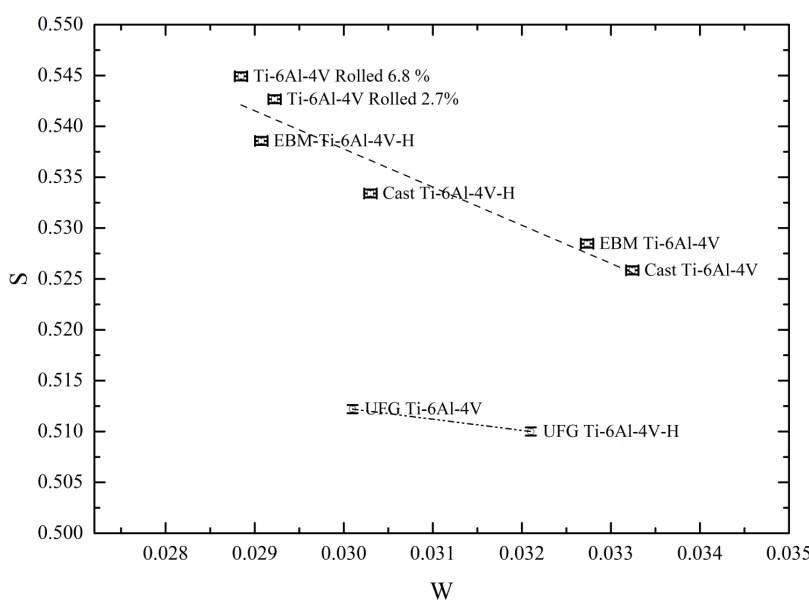

Fig. 2. $S-W$ plot for the Ti-6Al-4V experimental samples.

The long-lived component $\tau_{B}=276 \pm 6$ ps is responsible for the annihilation of positrons in complex hydrogenvacancy clusters $m \mathrm{~V}-n \mathrm{H}$ (where $m$ is the number of vacancies in cluster and $n$ is the number of hydrogen atoms associated with a cluster) [27].

In EBM $\mathrm{Ti}-6 \mathrm{Al}-4 \mathrm{~V}$ alloy, there are two positron lifetime components responsible for the annihilation of positrons trapped by dislocations $\left(\tau_{A}\right)$ and tetravacancies $\left(\tau_{B}=290 \pm 5 \mathrm{ps}\right)$. After hydrogenation, the intensity of the dislocation component increases 4.7 times, while the lifetime of the long-lived component decreases significantly (to $207 \mathrm{ps)}$ with intensity growing to $14 \%$. Thus, the concentration of dislocations increases and hydrogenvacancy complexes $(\mathrm{V}-1 \mathrm{H})$ are formed upon hydrogenation of EBM Ti-6Al-4V alloy [27].

In UFG Ti-6Al-4V alloy, an intense (71\%) component is observed with a lifetime of $171 \pm 2 \mathrm{ps,} \mathrm{which} \mathrm{can} \mathrm{be}$ associated with the annihilation of positrons trapped by dislocations or low-angle boundaries [13]. In this case, CDBS data is used to determine the prevailing type of defects. The $S-W$ plot obtained by $O X$ cross-section of the two-dimensional spectrum for the experimental $\mathrm{Ti}-6 \mathrm{Al}-4 \mathrm{~V}$ samples is presented in Fig. 2. CDBS results for cast $\mathrm{Ti}-6 \mathrm{Al}-4 \mathrm{~V}$ samples after cold rolling to various deformation degrees are added to the plot for comparison. The predominant type of defects after cold rolling are dislocations, so this type of defect will also be prevalent for all collinear experimental values in $S-W$ plot.
Thus, the predominant positron trapping center in UFG $\mathrm{Ti}-6 \mathrm{Al}-4 \mathrm{~V}$ alloy before and after hydrogenation is low-angle boundaries. Also, these samples are characterized by the presence of a long-lived component with a lifetime of $\sim 290 \mathrm{ps}$, which is associated with the annihilation of positrons trapped by vacancy or hydrogenvacancy complexes.

\section{Conclusion}

This article aimed to study the effect of the initial defect structure on defects accumulation in a titanium $\mathrm{Ti}-$ $6 \mathrm{Al}-4 \mathrm{~V}$ alloy. The series of measurements were carried out for cast, electron beam melting, and ultrafine-grained $\mathrm{Ti}-6 \mathrm{Al}-4 \mathrm{~V}$ alloys before and after hydrogenation. Samples are found to differ significantly in its initial defective structure. Annealed cast alloy is defect-free material. EBM Ti-6Al-4V alloy is characterized by an increased concentration of dislocations and vacancies complexes, and low-angle boundaries, and vacancy complexes are the main types of defects in UFG Ti-6Al-4V alloy. After hydrogenation, an increase in the concentration of dislocation defects was discovered for all samples. Besides, for cast and EBM alloys the growth of long-lived component intensities was observed, which indicates the formation of hydrogen-vacancy defects.

\section{Acknowledgments}

The research was funded by the Russian Science Foundation No. 17-79-20100.

\section{References}

[1] V. Madina, I. Azkarate, Int. J. Hydrogen Energy 34, 5976 (2009).

[2] M.K. Dunstan, J.D. Paramore, Z.Z. Fang, P. Sun, Mater. Sci. Eng. A 764, 138244 (2019).

[3] I.P. Mishin, G.P. Grabovetskaya, O.V. Zabudchenko, E.N. Stepanova, Russ. Phys. J. 57, 423 (2014).

[4] S.-W. Baek, E.J. Song, J.H. Kim, M. Jung, U.B. Baek, S.H. Nahm, Scr. Mater. 130, 87 (2017).

[5] D.B. Shan, Y.Y. Zong, Y. Lv, B. Guo, Scr. Mater. 58, 449 (2008).

[6] E. Tal-Gutelmacher, A. Pundt, R. Kirchheim, Scr. Mater. 62, 709 (2010).

[7] J. Č́žzek, J. Mater. Sci. Technol. 34, 577 (2018). 
[8] A.N. Singh, Appl. Spectrosc. Rev. 51, 359 (2016).

[9] R.Z. Valiev, Y. Estrin, Z. Horita, T.G. Langdon, M.J. Zehetbauer, Y.T. Zhu, Mater. Res. Lett. 4, 1 (2016).

[10] R.N. Harsha, V. Mithun Kulkarni, B. Satish Babu, Mater. Today Proc. 5, 22340 (2018).

[11] R. Valiev, Nat. Mater. 3, 511 (2004).

[12] J. Stráský, M. Janeček, I. Semenova, J. Čížek, K. Bartha, P. Harcuba, V. Polyakova, S. Gatina, in: Titanium in Medical and Dental Applications, Elsevier, 2018, p. 455.

[13] E. Stepanova, Y. Bordulev, V. Kudiiarov, R. Laptev, A. Lider, J. Xinming, AIP Conf. Proc. 1772, 030016 (2016).

[14] Y. Zhong, L.E. Rännar, L. Liu, A. Koptyug, S. Wikman, J. Olsen, D. Cui, Z. Shen, J. Nucl. Mater. 486, 234 (2017).

[15] V. Klimenov, A. Klopotov, V. Fedorov, Y. Abzaev, A. Batranin, K. Kurgan, D. Kairalapov, AIP Conf. Proc. 1909, 020085 (2017).

[16] G.P. Grabovetskaya, I.P. Mishin, E.N. Stepanova, I.P. Chernov, D.Y. Bulynko, Steel Transl. 45, 111 (2015).

[17] D. Giebel, J. Kansy, Mater. Sci. Forum 666, 138 (2010).
[18] D. Giebel, J. Kansy, Phys. Proced. 35, 122 (2012).

[19] M. Petriska, V. Sabelová, V. Slugeň, Defect Diffus. Forum 373, 71 (2017).

[20] J. Čížek, M. Vlček, I. Procházka, Nucl. Instrum. Methods Phys. Res. A 623, 982 (2010).

[21] K. Bartha, P. Zháňal, J. Stráský, et al., J. Alloys Comp. 788, 881 (2019).

[22] F. Lukáč, J. Čižek, J. Knapp, I. Procházka, P. Zháňal, R.K. Islamgaliev, J. Phys. Conf. Ser. 674, 012007 (2016).

[23] P. Hruška, J. Čížek, F. Lukáč, J. Knapp, S. Mašková, J. Drahokoupil, O. Melikhova, I. Procházka, Def. Diff. Forum 373, 122 (2017).

[24] P. Hruška, J. Čížek, J. Knapp, O. Melikhova, L. Havela, S. Mašková, F. Lukáč, Acta Phys. Pol. A 132, 1606 (2017).

[25] J.M. Campillo Robles, E. Ogando, F. Plazaola, J. Phys. Condens. Matter 19, 176222 (2007).

[26] J.M. Robles, E. Ogando, F. Plazaola, J. Phys. Conf. Ser. 265, 012006 (2011).

[27] R.S. Laptev, V.N. Kudiiarov, Y.S. Bordulev, A.A. Mikhaylov, A.M. Lider, Prog. Nat. Sci. Mater. Int. 27, 105 (2017). 